\title{
A Guide to Water Free Lithium Bis(oxalate) Borate (LiBOB)
}

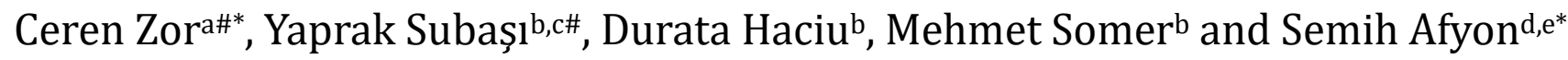

${ }^{\mathrm{a}}$ University of Oxford, Department of Materials, Oxford, United Kingdom.

${ }^{\mathrm{b}}$ Koç University, Department of Chemistry, Sarıyer, Istanbul, 34450, Turkey.

${ }^{\mathrm{c}}$ Koç University Boron and Advanced Materials Application and Research Center (KUBAM),

Istanbul, 34450, Turkey.

${ }^{\mathrm{d}}$ Gebze Technical University, Energy Technologies Institute, Gebze, Kocaeli, 41400, Turkey.

${ }^{\mathrm{e}}$ Gebze Technical University, Department of Mechanical Engineering, Gebze, Kocaeli, 41400, Turkey.

*Corresponding authors:

E-mail: safyon@gtu.edu.tr, ceren.zor@materials.ox.ac.uk

${ }^{\#}$ C. Zor and Y. Subasi should be considered co-first authors.

\begin{abstract}
Lithium bis(oxalate)borate, $\mathrm{LiB}\left(\mathrm{C}_{2} \mathrm{O}_{4}\right)_{2}(\mathrm{LiBOB})$, is one of the most important electrolyte additives for Li-ion batteries (LIBs) due to its numerous advantages such as thermal stability, good solubility in organic solvents, high conductivity, and low cost as well as providing safer operations with superior electrochemical performance compared to conventional electrolyte combinations. However, the use of LiBOB is limited due to slight instability issues under ambient conditions that might require extra purification steps and might result in poorer performances in real systems. Here, we address some of these issues and report the high purity water free LiBOB synthesized with fewer processing steps employing lithium carbonate, oxalic acid, and boric acid as lowcost starting materials, and via ceramic processing methods under protective atmosphere. The physical and chemical characterizations of both anhydrous and monohydrate phases are performed with X-ray powder diffraction (XRPD), Fourier-transform infra-red spectroscopy (FTIR), Raman spectroscopy and scanning electron microscopy (SEM) analyses to determine the degree of the purity and the formation of impurities like $\mathrm{LiBOB}_{2} \mathrm{H}_{2} \mathrm{O}, \mathrm{HBO}_{2}$ and $\mathrm{Li}_{2} \mathrm{C}_{2} \mathrm{O}_{4}$ as a result of the aging investigations performed. Differential thermal analysis (DTA) is applied to determine the optimum synthesis conditions for anhydrous LiBOB and to analyze the water loss and the decomposition of $\mathrm{LiBOB} \cdot \mathrm{H}_{2} \mathrm{O}$. Aging experiments with the water free $\mathrm{LiBOB}$ are carried out to evaluate the effect of humidity in the phase changes and resulting impurities under various conditions. The detrimental effect of even slightest humidity conditions is shown, and protective measures during and after the synthesis of LiBOB are discussed. Anhydrous LiBOB could be widely used as an electrolyte additive to improve the overall electrochemical performances for LIBs through development of a protective solid electrolyte interphase (SEI) on the surface of high voltage cathodes and bringing about superior electrochemical properties with increased cycling stability, rate capability and coulombic efficiency, if synthesized, purified, and handled properly before use in real electrochemical systems.
\end{abstract}

KEYWORDS: Li-ion batteries, LiBOB, humidity, electrolyte, additive 


\section{INTRODUCTION}

Electrolyte salts and additives play a crucial role in increasing the cycle life, capacity and safety of batteries especially for high voltage applications ${ }^{1-3}$. Lithium bis(oxalate) borate, $\mathrm{LiB}\left(\mathrm{C}_{2} \mathrm{O}_{4}\right)_{2}(\mathrm{LiBOB})$, is one of the most widely used electrolyte additives in $\mathrm{Li}$-ion batteries (LIBs) and has a potential to be an alternative of the commercially used lithium hexafluorophosphate $\left(\mathrm{LiPF}_{6}\right)$ as an electrolyte salt when dissolved in suitable solvents. LiBOB provides electrochemical stability at high applied potentials and high thermal stability under different electrochemical conditions ${ }^{4-6}$. LiBOB also promotes the formation of a protective solid-electrolyte interface (SEI) layer; thus increasing capacity and cycle life when used as an electrolyte additive ${ }^{7-14}$.

LiBOB can address the need for stable electrolyte compositions for high voltage cathode materials and applications. In a mixed solvent system $(\gamma$ butyrolactone and dimethyl carbonate), it was shown that $\mathrm{LiBOB}$ provides oxidative stability up to $5.3 \mathrm{~V}$ in Li-ion batteries ${ }^{3,15}$, whereas $\mathrm{LiPF}_{6}$ can be only employed up to $4.5 \mathrm{~V}$. The thermal stability of bulk $\mathrm{LiPF}_{6}$ is $80{ }^{\circ} \mathrm{C}$, and it is safe to use up to $50{ }^{\circ} \mathrm{C}$ in LIBs. Additionally, at higher temperatures, $\mathrm{LiPF}_{6}$ is susceptible to decompose into $\mathrm{LiF}$ and $\mathrm{PF}_{5}$ resulting in low electrochemical performances and safety issues 8,16 . On the other hand, bulk LiBOB decomposes at $300{ }^{\circ} \mathrm{C}$ and it is stable up to $70^{\circ} \mathrm{C}$ in LIBs ${ }^{17}$. There are several other reports where LiBOB enables a stable operation at voltages higher than $4.5 \mathrm{~V}^{18-20}$. Besides, LiBOB provides safer operation for Li-ion batteries not only due to its high thermal stability but also due to the protective SEI formation. SEI layer formation does not only play an active role only in the first cycle in the battery; yet, SEI keeps growing and changing with processes such as dissolution and precipitation ${ }^{21,22}$. Thus, understanding the SEI chemistry and stabilizing the SEI are important challenges in the development of long-life and safe LIBs, as well.

Other common Li-ion battery salts such as $\mathrm{LiPF}_{6}$, $\mathrm{LiAsF}_{6}$, and $\mathrm{LiClO}_{4}$ were shown to decompose to form corrosive and reactive chemicals ${ }^{23}$. The high oxidation state of $\mathrm{Cl}(\mathrm{VII})$ in $\mathrm{LiClO}_{4}$ causes reactions with a range of organic solvents ${ }^{24}$, and As(III) and $\mathrm{As}(0)$ that form during redox reactions involving Li$\mathrm{AsF}_{6}$ are toxic ${ }^{25}$, and LiTf based electrolytes are highly corrosive ${ }^{23}$. On the other hand, LiBOB has received great interest owing to its superior properties such as thermal stability, good solubility in organic solvents, improved cycling stability with high voltage cathodes, environmentally friendliness, and low cost 9 , $11,14,26,27$. LiBOB was also shown to protect graphite anodes from exfoliation in PC-based electrolytes and to develop a SEI on the surface of carbon based cathode materials ${ }^{6}$. Additionally, corrosive and dangerous by-products such as HF do not evolve upon cycling when $\mathrm{LiBOB}$ is used instead of $\mathrm{LiPF}_{6}$. Unlike $\mathrm{LiPF}_{6}$ and other salts such as $\mathrm{LiClO}_{4}, \mathrm{LiAsF}_{6}$ and LiTf, LiBOB directly forms a protective SEI independent of the carbonate electrolyte solvent employed. Additionally, other potentially corrosive and dangerous byproducts such as $\mathrm{PF}_{5}$ and $\mathrm{LiF}$ do not evolve upon cycling when LiBOB is used ${ }^{28-30}$. If the applications of LiBOB as an additive are considered, Pieczonka et al. observed that the addition of 1 wt.\% LiBOB in traditional electrolytes increases the cycling stability and coulombic efficiency for a high voltage spinel/graphite battery system, and the addition of 3 wt.\% LiBOB eliminated the $\mathrm{PF}_{5}$ decreasing the $\mathrm{Mn}$ dissolution from the $\mathrm{Li}_{1-\mathrm{x}} \mathrm{Ni}_{0.42} \mathrm{Fe}_{0.08} \mathrm{Mn}_{1.5} \mathrm{O}_{4}$ (LNFMO) cathode ${ }^{19}$. In another study, Lee and coworkers employed LiBOB as an electrolyte additive to develop a protective SEI for high potential $\mathrm{Li}_{1.17} \mathrm{Ni}_{0.17} \mathrm{Mn}_{1.5} \mathrm{Co}_{0.17} \mathrm{O}_{2}$ cathodes improving the cycling stability and rate capability via eliminating the electrolyte decomposition ${ }^{31}$.

Although LiBOB is a very promising electrolyte salt and additive for Li-ion batteries, up to date, there are only few reports ${ }^{32-34}$ investigating different synthetic routes. LiBOB is mainly synthesized using high-cost lithium salts such as $\mathrm{LiBH}_{4}$ and $\mathrm{LiOH}$ in most of the current reports ${ }^{32,33,35}$. In addition, to the best of our knowledge, LiBOB. $\mathrm{H}_{2} \mathrm{O}$ is present as a by-product in all reported LiBOB synthesis methods in the literature. Depending on the reactants used in LiBOB synthesis, impurities such as lithium oxalate and lithium carbonate were also detected in the final product. In addition, there is a lack of research focusing on the stability of this important electrolyte salt and additive under humidity during and after the synthesis, and under prolonged air exposure. Therefore, herein, we focus on these issues and report on the importance of new synthetic routes and humidity conditions to obtain a high purity water free LiBOB. We synthesize anhydrous and higher purity LiBOB using low cost starting materials and fewer processing steps compared to most prevalent synthesis methods in the literature. Avoiding moisture and impurities in LiBOB and such electrolyte salts are vital for the performance of LIBs. Thus, we also underline the importance of synthesizing and employing LiBOB under protective atmosphere to eliminate hydrous phase and impurity 
formation by investigating the aging results of the synthesized high purity salt under atmospheric conditions.

\section{EXPERIMENTAL SECTION}

\subsection{Synthesis of anhydrous LiBOB}

LiBOB is synthesized using lithium carbonate $\left(\mathrm{Li}_{2} \mathrm{CO}_{3}, \geq 99 \%\right.$, Alfa Aesar), oxalic acid $\left(\mathrm{C}_{2} \mathrm{H}_{2} \mathrm{O}_{4}, \geq\right.$ $98 \%$, Alfa Aeasar), and boric acid $\left(\mathrm{H}_{3} \mathrm{BO}_{3}, \geq 99 \%\right.$, Alfa Aesar) as starting materials. Stoichiometric amounts of the compounds (following the equation in Figure 1d) are mixed and ground in a mortar. Excess amount of deionized water is added to the powder mixture, and the mixture is stirred continuously at 80 ${ }^{\circ} \mathrm{C}$ under ambient conditions until all water is evaporated. A pellet made from this powder precursor is placed in a glassy carbon boat and covered/protected with the same precursor powder. Then, the reaction boat is placed in a quartz tube within a horizontal tubular furnace, and the reaction is carried under protective atmosphere (Ar, $\mathrm{N}_{2}$ or dry air) at $250{ }^{\circ} \mathrm{C}$ for 10-15 hours. The products are transferred into an $\mathrm{Ar}$ glovebox $\left(\mathrm{O}_{2}\right.$ and $\left.\mathrm{H}_{2} \mathrm{O}<1 \mathrm{ppm}\right)$ without exposure to ambient atmosphere. After the synthesis, the protective powder is discarded, and the anhydrous LiBOB pellet is ground in a mortar in the glovebox. Aging of the anhydrous $\mathrm{LiBOB}$ powder is done under ambient conditions (at RT, and $70 \%$ Average Relative $\mathrm{Hu}-$ midity). 2-3 grams of LiBOB powder is placed in semi-closed autoclave bottles and left in fume hoods with ventilation for 5, 15, 30 minutes, and 2 days.

\subsection{Characterization of LiBOB}

The phase and purity of the samples are determined by X-ray powder diffraction (XRPD) method using a Bruker D8 Advance X-ray diffractometer, and $\mathrm{Cu} \mathrm{K}_{\alpha 1}$ radiation (operated at $40 \mathrm{~mA}, 40 \mathrm{kV}$ ). The purity of the as synthesized LiBOB and impurities forming upon aging are further characterized by vibrational spectroscopy analyses. Fourier-transform infra-red spectroscopy (FTIR) is performed on a Thermo Scientific Nicolet iS10 spectrometer with a single reflection diamond attenuated total reflectance (ATR) module, and Renishaw inVia Raman microscope equipped with a $532 \mathrm{~nm}$ laser as the excitation source is used to perform Raman spectroscopy. The morphology of the as synthesized and aged powders is investigated by scanning electron microscopy (SEM) analysis using a Zeiss Ultra Plus field emission GeminiSEM. Differential thermal analysis (DTA) is utilized to monitor the reaction and any exothermic and endothermic reactions in the selected temperature range using a Netzsch STA 449 thermal analysis system.

\section{RESULTS AND DISCUSSION}

LiBOB is synthesized in high purity following the procedure depicted in Figure 1a and 1b. The phase and purity of as-synthesized $\mathrm{LiBOB}$ is investigated via XRPD analysis by comparing the experimental reflection pattern with the calculated reflection pattern of LiBOB (ICSD 281623) (Figure 1c). The XRPD pattern of the as-synthesized LiBOB match the theoretical pattern, and the reflections belong only to anhydrous LiBOB ${ }^{36}$. This finding shows that single phase anhydrous LiBOB could be obtained in a single synthetic step without the need of any extra recrystallization steps to eliminate $\mathrm{LiBOB} \cdot \mathrm{H}_{2} \mathrm{O}$. The lack of any other reflections belonging to possible impurity phases shows that they are under $\sim 1 \mathrm{wt}-\%$. Most importantly, LiBOB. $\mathrm{H}_{2} \mathrm{O}$ which is the main impurity in the synthesis that could also cause parasitic reactions in LIBs is not observed. Key points in achieving high purity anhydrous LiBOB with the experimental design were conducting the reaction under inert atmosphere (under argon, nitrogen, and dry air) and protecting the pellet with the precursor powder following well-known ceramic processing methods (Figure 1a, Figure 1c and Figure S1). 
(a)
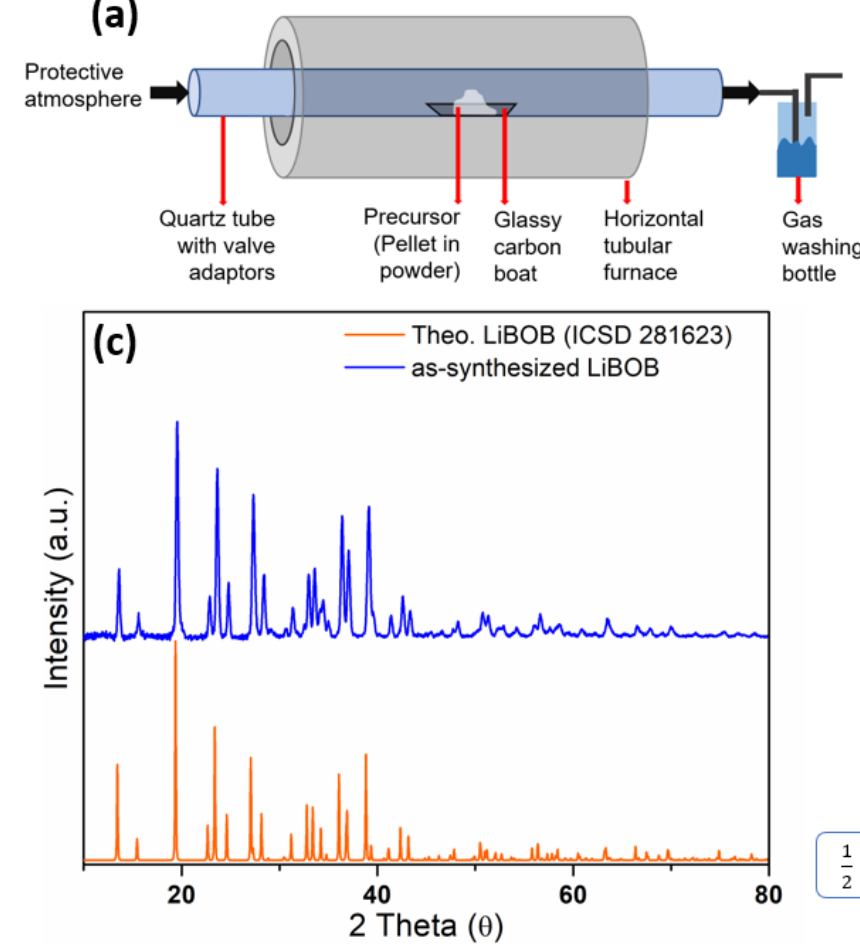

(b)

Lithium Carbonate + Boric Acid + Oxalic Acid

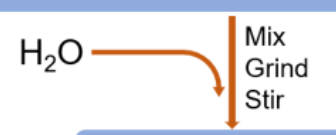

Drying at $120^{\circ} \mathrm{C}$

Pellet

Rxn under protective gas, @ $250^{\circ} \mathrm{C}, 15$ hrs

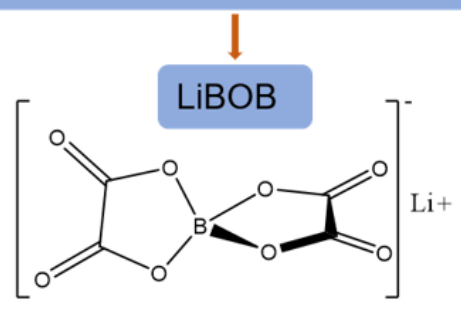

(d)

$\frac{1}{2} \mathrm{Li}_{2} \mathrm{CO}_{3}+2 \mathrm{C}_{2} \mathrm{H}_{2} \mathrm{O}_{4}+\mathrm{H}_{3} \mathrm{BO}_{3} \rightarrow \mathrm{LiB}\left(\mathrm{C}_{2} \mathrm{O}_{4}\right)_{2} \cdot x \mathrm{H}_{2} \mathrm{O}+\frac{1}{2} \mathrm{CO}_{2}+\left(\frac{7}{2}-\mathrm{x}\right) \mathrm{H}_{2} \mathrm{O}$

Figure 1. (a) A schematic representation of the experimental setup for high purity anhydrous LiBOB synthesis. $\mathrm{Ar}, \mathrm{N}_{2}$ and dry air are employed as protective gases (please see Supplementary Figure $\mathrm{S} 1$ for the $\mathrm{N}_{2}$ and dry air synthesis results). (b) Processing steps used in the synthesis of high purity anhydrous LiBOB. (c) XRPD patterns of theoretical LiBOB (ICSD 281623) ${ }^{36}$ (orange) and as-synthesized LiBOB (blue). Reflections belonging only to LiBOB are observed in the XRPD pattern for the synthesized sample. (d) The overall chemical equation for the LiBOB synthesis reaction.

The reaction of the precursor pellet was monitored via differential thermal analysis (DTA), and different synthesis conditions were also carried out at varied temperatures to determine the optimum temperature window for the high purity LiBOB synthesis (Figure 2). From the XRPD analysis and DTA data, 225 - 300 ${ }^{\circ} \mathrm{C}$ temperature range could be claimed to be the optimum range for this synthesis. The XRPD and DTA findings show that anhydrous $\mathrm{LiBOB}$ decompose into lithium oxalate $\left(\mathrm{Li}_{2} \mathrm{C}_{2} \mathrm{O}_{4}\right)$ and other amorphous phases at temperatures ca. $>315{ }^{\circ} \mathrm{C}$ and at temperatures below $250{ }^{\circ} \mathrm{C}$ either monohydrate phase is observed or the reaction is not complete (Figure 2a). According to the Reference intensity ratio (RIR) method ${ }^{37-39}$, the percentage of anhydrous LiBOB for as-synthesized samples at $200{ }^{\circ} \mathrm{C}$, and $250{ }^{\circ} \mathrm{C}$ was found $\sim 95 \mathrm{wt}-\%$ and $\sim 99.0 \mathrm{wt}-\%$, respectively. Humidity and impurities in LiBOB have detrimental effects on the performance of Li-ion batteries ${ }^{40}$, and although it was claimed that monohydrate of LiBOB is stable ${ }^{41}$, we show that hydrated LiBOB could decompose into
$\mathrm{HBO}_{2}, \mathrm{Li}_{2} \mathrm{C}_{2} \mathrm{O}_{4}$ when exposed to air (Figure S2). The presence of such impurities in electrolyte solution could cause capacity fading and safety problems under extensive cycling. 

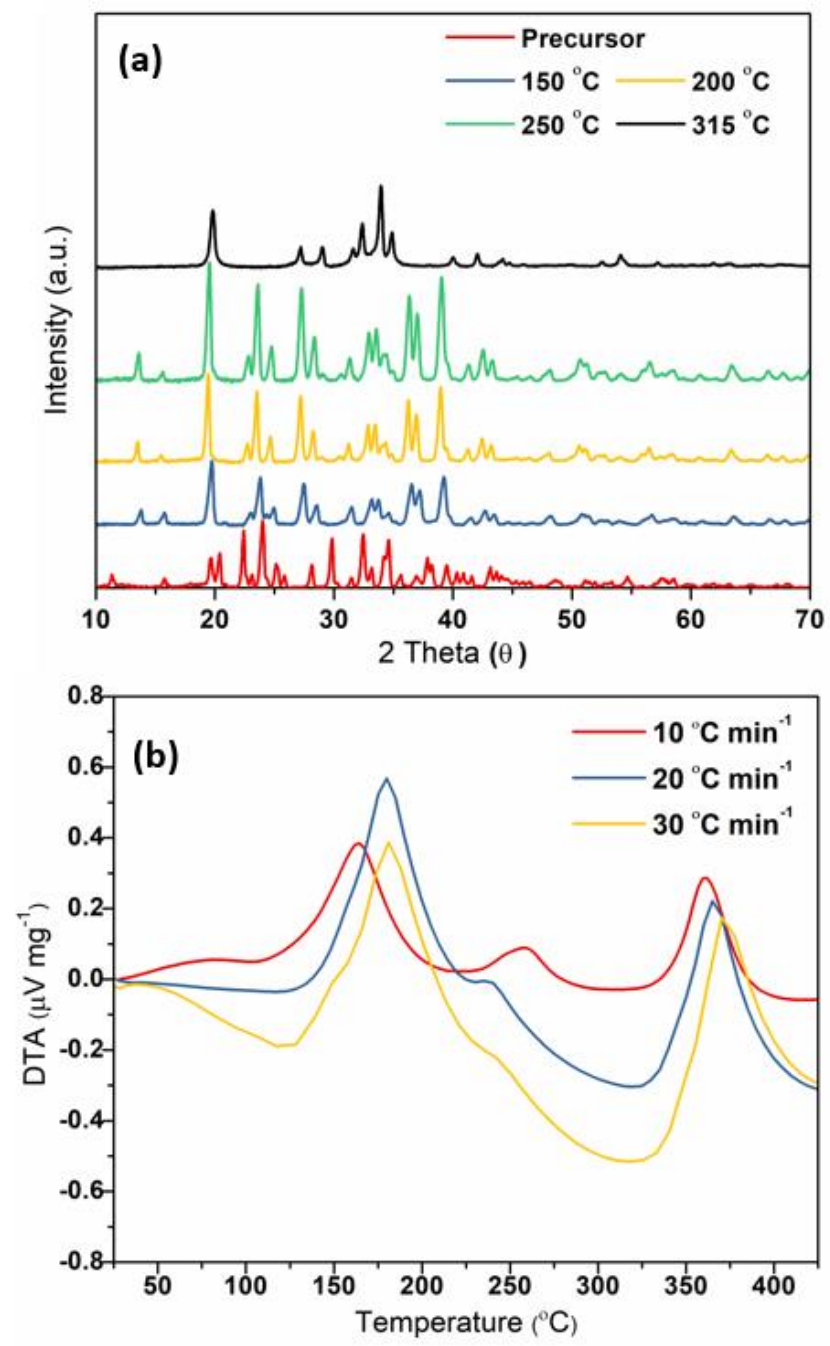

Figure 2. (a) XRPD patterns for the precursor and samples synthesized at $150{ }^{\circ} \mathrm{C}$ (blue), $200{ }^{\circ} \mathrm{C}$ (yellow), $250{ }^{\circ} \mathrm{C}$ (green) and $315{ }^{\circ} \mathrm{C}$ (black). (b) DTA data taken at different heating rates showing the reaction temperature for LiBOB synthesis and decomposition temperature of the synthesized LiBOB.

Scanning electron microscopy (SEM) was employed to further understand the particle morphologies and the effect of humidity on those. A homogeneous distribution of particles is observed in SEM images for the samples calcined at temperatures between 250 $300{ }^{\circ} \mathrm{C}$ (Figure 3a, c, d). These anhydrous LiBOB particles are few microns in size and prism shaped, whereas synthesis at lower temperatures $\left(<150^{\circ} \mathrm{C}\right)$ and the product after prolonged air exposure yield rumbled morphologies without any well-defined structures. (Figure 3b, Figure S4). The detrimental effect of humidity on high purity LiBOB can be easily observed via SEM analysis, as well (Figure S3). The morphology of the anhydrous LiBOB particles start changing after $\leq 5$-minute-long exposure to air, and curvatures and pores start to form on the surface of prisms (Figure S3).
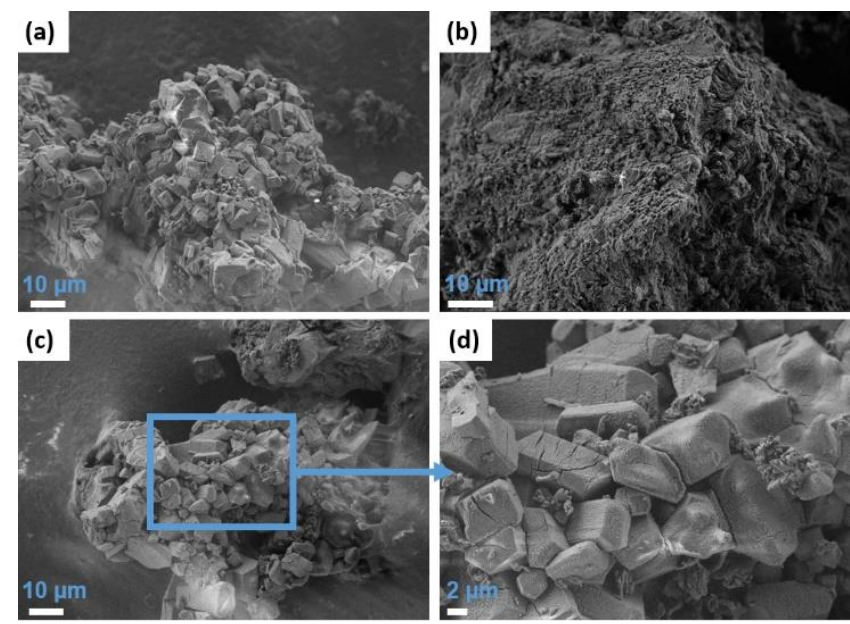

Figure 3. (a), (c) SEM micrographs showing the particle size and morphology of anhydrous LiBOB synthesized at $250{ }^{\circ} \mathrm{C}$. (b) Morphology of the products synthesized at $150{ }^{\circ} \mathrm{C}$. (d) Magnified region from c, displaying $\mathrm{LiBOB}$ crystals.

In order to analyze the effect of prolonged air exposure to this important electrolyte additive, and to further investigate the influence of humidity in phase changes, aging experiments were performed. Aging of the anhydrous LiBOB powder was done under ambient conditions (at RT $\left(\sim 25^{\circ} \mathrm{C}\right)$, and $70 \%$ Average Relative Humidity) for 5, 15, 30 minutes and 2 days. The effect of humidity is first investigated through XRPD analysis. XRPD powder patterns in Figure 4a show that as-synthesized powder consists of only anhydrous LiBOB phase, and 42 wt- $\%$ monohydrate phase ( $\mathrm{LiBOB} . \mathrm{H}_{2} \mathrm{O}$ ) forms after 5 minutes of aging under given conditions according to the RIR method. After only 15 minutes of exposure to air under given conditions, almost all of the anhydrous LiBOB turns into LiBOB. $\mathrm{H}_{2} \mathrm{O}$, and the complete hydration occurs after 30 minutes of aging (Figure 4a \& $\mathbf{4 b}$ ). The presence of water in the structure can be further confirmed by DTA analysis (Figure 4c). The structural water is given from the monohydrate phase at $\sim 150{ }^{\circ} \mathrm{C}$, and the phase decomposition into $\mathrm{Li}_{2} \mathrm{C}_{2} \mathrm{O}_{4}$ and other amorphous phases start at $~ 315$ ${ }^{\circ} \mathrm{C}$. These findings signify the importance of synthesizing and preserving $\mathrm{LiBOB}$ under protective atmos- 
phere. Since purity of electrolyte salts and additives play a crucial role in the cycle life and safety of LIBs ${ }^{42}$, the measures taken here in the synthesis of LiBOB can be considered as critical necessary steps.

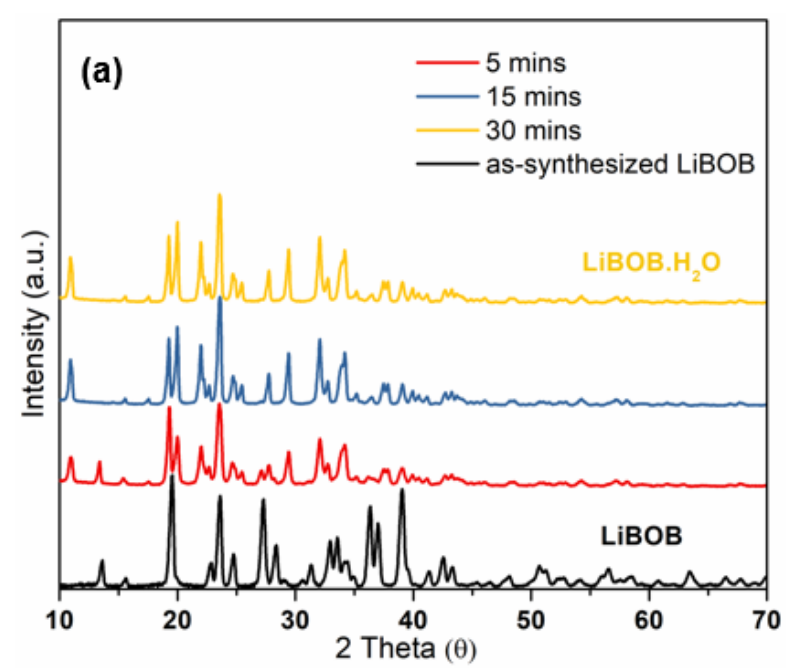

(b)

\begin{tabular}{|c|c|c|c|c|}
\hline (b) & As is & 5 mins & 15 mins & 30 mins \\
\hline$\%$ LiBOB & $\begin{array}{c}>99.0 \\
\text { wt } \%\end{array}$ & $\begin{array}{l}41.9 \\
\text { wt } \%\end{array}$ & 6.2 wt $\%$ & - wt $\%$ \\
\hline$\%$ LiBOB. $\mathrm{H}_{2} \mathrm{O}$ & - wt $\%$ & $\begin{array}{l}58.1 \\
\text { wt } \%\end{array}$ & 93.8 wt $\%$ & $\begin{array}{c}>99.0 \\
w t \%\end{array}$ \\
\hline
\end{tabular}

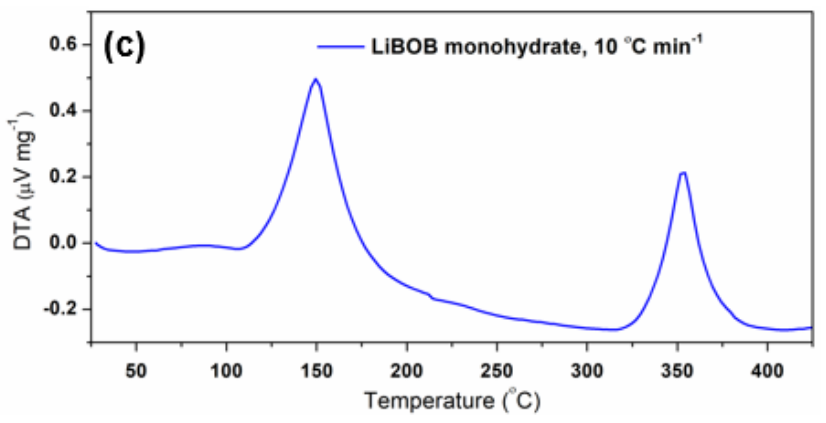

Figure 4. (a) XRPD patterns of the as-synthesized and aged (5, 15, and 30 minutes) LiBOB samples. (b) Phase composition of $\mathrm{LiBOB}$ and $\mathrm{LiBOB} . \mathrm{H}_{2} \mathrm{O}$ in assynthesized and aged samples calculated via reference intensity ratio (RIR) method. (c) DTA analysis showing the water loss and decomposition of $\mathrm{LiBOB}^{\mathrm{H}} \mathrm{H}_{2} \mathrm{O}$.

The vibrational spectroscopy analysis is in good agreement with XRPD and DTA analyses in terms of confirming the high purity LiBOB phase after the synthesis, and verifies the humidity effect after aging. Both Raman and FTIR spectra of the as-synthesized phase clearly show the high purity of the as-prepared
LiBOB after the synthesis ${ }^{10,40,43}$ and no major impurity phases are observed (Figure 5a \& Figure 5b). In the FTIR spectrum (Figure 5b) of the LiBOB phase, the strong absorption peak at $1765-1825 \mathrm{~cm}^{-1}$ could be assigned to the stretching vibrations of $\mathrm{C}=\mathrm{O}$ bond, whereas the region of $980-1370 \mathrm{~cm}^{-1}$ is attributed to the $\mathrm{C}-\mathrm{O}$ and $\mathrm{B}-\mathrm{O}$ stretching modes ${ }^{10,32}$. To analyze the hydration of the anhydrous phase, the FTIR spectra from the aged LiBOB samples were also collected. The water absorption peak intensity at ca. $3500 \mathrm{~cm}^{-1}$ increases with the aging time, and several absorption peaks in the range of $1500-800 \mathrm{~cm}^{-1}$ shift-change due to the structural deterioration of $\mathrm{LiBOB}^{40,44}$. It should be also noted that a very small water peak might be visible in the spectrum of the as-synthesized sample, since the measurement was not done in a protective atmosphere, so the sample was exposed to air for a minute. As the aging time increases, it is also evident that there is $\mathrm{Li}_{2} \mathrm{C}_{2} \mathrm{O}_{4}$ formation in samples with the observation of small intensity peaks at 1658 and 778 $\mathrm{cm}^{-1} 40,45$. These finding are also consistent with XRPD patterns of the aged LiBOB for two days and the decomposed LiBOB (Figure S2, Figure 2a-315 ${ }^{\circ} \mathrm{C}$ pattern). As shown in the Figure $\mathbf{S 2}$, in addition to the diffraction pattern of the $\mathrm{LiBOB} . \mathrm{H}_{2} \mathrm{O}$, reflections at $20.08^{\circ}$ and $27.88^{\circ}$ could be attributed to the formation of $\mathrm{HBO}_{2}$, and reflections at $22.06^{\circ}$ and $29.48^{\circ}$ indicate the presence of $\mathrm{Li}_{2} \mathrm{C}_{2} \mathrm{O}_{4}$, as similarly observed by other investigators ${ }^{33,46}$. 

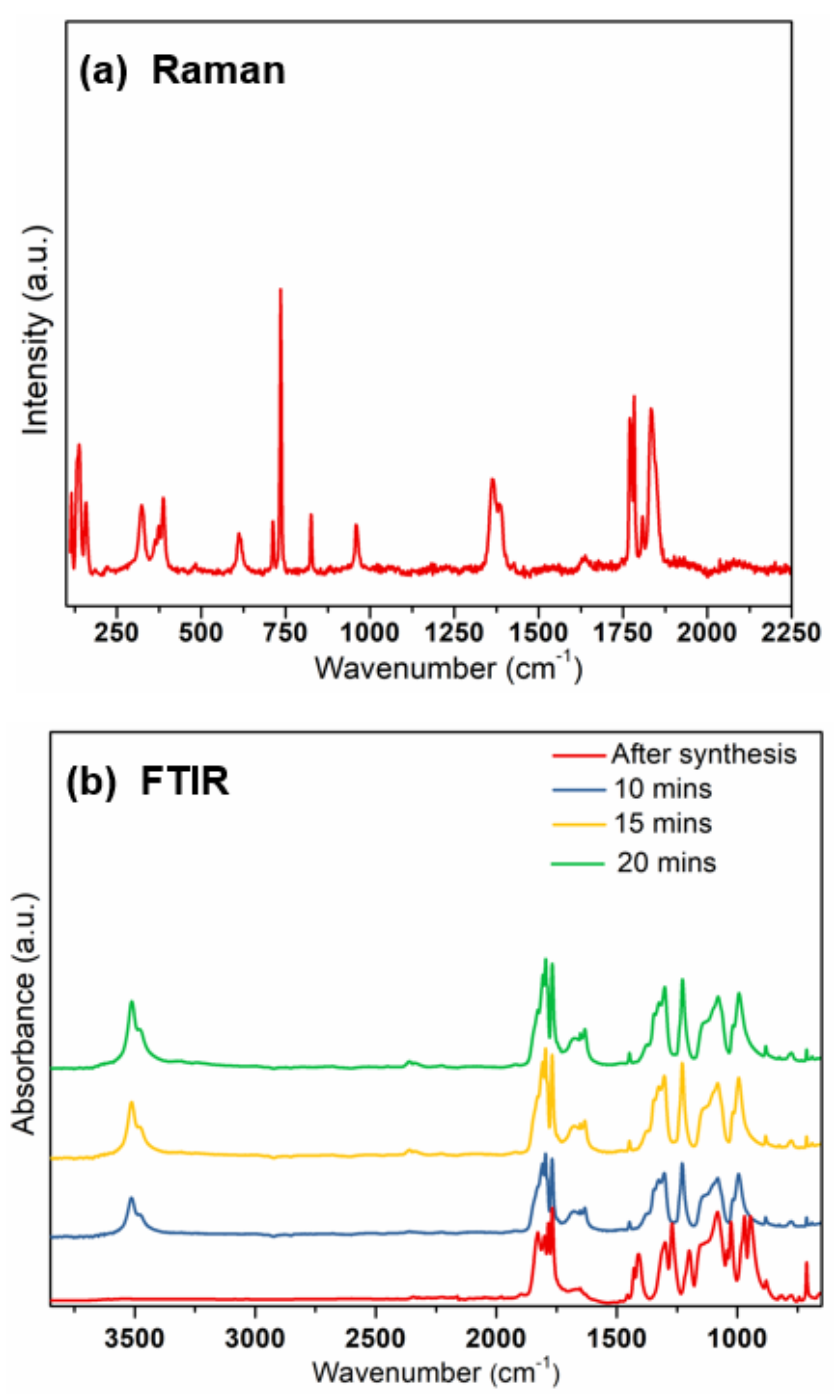

Figure 5. (a) Raman spectra of anhydrous LiBOB. (b) FTIR spectra of as synthesized and aged LiBOB showing the formation of monohydrate phase and secondary phases upon exposure to ambient conditions.

To sum up, the detrimental effect of humidity during and after the synthesis of LiBOB is evident with the monohydrate phase formation that could further decompose mainly into $\mathrm{Li}_{2} \mathrm{C}_{2} \mathrm{O}_{4}$ and amorphous other phases. These impurities could of course be eliminated through repeated recrystallization steps with polar aprotic organic solvents, but this would bring about additional complications, such as cost increases and environmental burden with the use of organic solvents. Therefore, high purity synthesis of anhydrous LiBOB with least possible steps is very important, and would decrease the number of recrystallization steps in case if they are needed. The employment and widespread application of LiBOB as an electrolyte additive in LIBs could be considered as limited in the current state-of-art. Yet, we think that this limitation is also present because of the unexpected or low quality results obtained due to the occurrence of impurities and hydrated phases ${ }^{40-42,47}$. This occurrence and impurities may not even be realized by the unsuspecting, as they are very easy to form as we have shown here. Nevertheless, with the proper use, LiBOB could be expected to bring superior electrochemical performances when it is used as an electrolyte additive for LIBs including cycling stability, rate capability, energy density and coulombic efficiency by preventing the electrolyte decomposition and the formation of dangerous byproducts. Additionally, a protective LiBOB-derived SEI will develop on the electrode surface enhancing the interfacial stability for high temperature operations.

\section{CONCLUSIONS}

LiBOB was synthesized under protective atmosphere using lithium carbonate, oxalic acid, and boric acid as low-cost starting materials by applying ceramic processing methods to achieve a high purity product. Aging investigations were also carried out to further evaluate the effect of humidity and the formation of $\mathrm{LiBOB} . \mathrm{H}_{2} \mathrm{O}$ and impurities such as $\mathrm{HBO}_{2}, \mathrm{Li}_{2} \mathrm{C}_{2} \mathrm{O}_{4}$ that are undesirable in applications for high performance LIBs. According to the DTA results, the synthesis temperatures above $315^{\circ} \mathrm{C}$ cause decomposition of anhydrous $\mathrm{LiBOB}$ into impurities and at temperatures below $200{ }^{\circ} \mathrm{C}$ the formation of the monohydrate phase may result in the capacity fade and poor cycling performance for LIBs. As shown from the XPRD data and FTIR and Raman spectra, the resulting salt is anhydrous and high purity over 99 wt- $\%$; thus, a higher purity is obtained with fewer and practical processing steps compared to some commercial products and LiBOB reported in the literature. XRPD analysis showed that $\sim 42 \mathrm{wt}-\%$ monohydrate phase ( $\mathrm{LiBOB} . \mathrm{H}_{2} \mathrm{O}$ ) formed only after 5 minutes of aging at RT-70 \% relative humidity, and only after 30 minutes of exposure to air under given conditions, the complete hydration occurred. From the SEM micrographs, consistent with the findings from XPRD and FTIR, the structural deterioration of LiBOB can also be tracked. The longer exposures in the time scale of days further decomposed LiBOB. $\mathrm{H}_{2} \mathrm{O}$ into other impurity phases, mainly $\mathrm{Li}_{2} \mathrm{C}_{2} \mathrm{O}_{4}$. Keeping the purity high and avoiding exposure to humidity in all pro- 
cessing steps are crucial for stable performance of batteries using LiBOB either as an electrolyte salt or additive and towards widespread applications, especially high voltage LIBs.

\section{ASSOCIATED CONTENT Supporting Information}

XRPD patterns of high purity anhydrous LiBOB synthesized using different protective gases i.e. under dry air and $\mathrm{N}_{2}$ atmosphere. XRPD pattern showing crystalline water, $\mathrm{HBO}_{2}, \mathrm{Li}_{2} \mathrm{C}_{2} \mathrm{O}_{4}$ formation after aging anhydrous LiBOB for 2 days under ambient conditions. SEM Micrographs for anhydrous LiBOB ages under ambient conditions showing changes in the prismatic morphology and formation of pores. SEM Micrographs showing the morphology of the products synthesized at $150-200{ }^{\circ} \mathrm{C}$.

\section{AUTHOR INFORMATION}

\section{Corresponding Authors}

Semih Afyon - ${ }^{d}$ Gebze Technical University, Energy Technologies Institute, Gebze, Kocaeli, 41400, Turkey.

${ }^{e}$ Gebze Technical University, Department of Mechanical Engineering, Gebze, Kocaeli, 41400, Turkey. Email:safyon@gtu.edu.tr.

Ceren Zor - ${ }^{a}$ University of Oxford, Department of Materials, Oxford, United Kingdom. Email: ceren.zor@materials.ox.ac.uk.

\section{Authors}

Yaprak Subaşı - ${ }^{b}$ Koç University, Department of Chemistry, Sarlyer, Istanbul, 34450, Turkey.

${ }^{c}$ Koç University Boron and Advanced Materials Application and Research Center (KUBAM).

Durata Haciu - ${ }^{b}$ Koç University, Department of Chemistry, Sarlyer, Istanbul, 34450, Turkey.

Mehmet Somer - ${ }^{b}$ Koç University, Department of Chemistry, Sarlyer, Istanbul, 34450, Turkey.

\section{Author Contributions}

\#Ceren Zor and Yaprak Subaşı should be considered co-first authors. All authors have given approval to the final version of the manuscript.

\section{CONFLICTS OF INTEREST}

There are no conflicts to declare.

\section{ACKNOWLEDGMENTS}

This study was financially supported by the National Boron Research Institute (BOREN), (No. 2018-3107-15-003). Yaprak Subaşı thanks BOREN for funding her scholarship. The authors thank Koç University Surface Science and Technology Center (KUYTAM) and Koç University Boron and Advanced Materials Application and Research Center (KUBAM) for the use of characterization facilities.

\section{REFERENCES}

1. Hofmann, A.; Höweling, A.; Bohn, N.; Müller, M.; Binder, J. R.; Hanemann, T., Additives for Cycle Life Improvement of High-Voltage LNMOBased Li-Ion Cells. ChemElectroChem 2019, 6 (20), 5255-5263.

2. Wu, S.; Lin, Y.; Xing, L.; Sun, G.; Zhou, H.; Xu, K.; Fan, W.; Yu, L.; Li, W., Stabilizing LiCoO2/Graphite at High Voltages with an Electrolyte Additive. ACS Applied Materials \& Interfaces 2019, 11 (19), 17940-17951.

3. Choi, N.-S.; Han, J.-G.; Ha, S.-Y.; Park, I.; Back, C.-K., Recent advances in the electrolytes for interfacial stability of high-voltage cathodes in lithium-ion batteries. RSC Advances 2015, 5 (4), 2732-2748.

4. Xiao, Z.; Liu, J.; Fan, G.; Yu, M.; Liu, J.; Gou, X.; Yuan, M.; Cheng, F., Lithium bis(oxalate)borate additive in the electrolyte to improve Li-rich layered oxide cathode materials. Materials Chemistry Frontiers 2020, 4 (6), 16891696.

5. Täubert, C.; Fleischhammer, M.; WohlfahrtMehrens, M.; Wietelmann, U.; Buhrmester, T., $\mathrm{LiBOB}$ as Electrolyte Salt or Additive for LithiumIon Batteries Based on LiNi0.8Co0.15A10.05O2/Graphite. Journal of The Electrochemical Society 2010, 157 (6), A721-A728. 
6. $\quad \mathrm{Xu}, \mathrm{K}$.; Zhang, S.; Jow, T. R., LiBOB as Additive in LiPF6-Based Lithium Ion Electrolytes. Electrochemical and Solid-State Letters 2005, 8 (7), A365-A368.

7. Liu, Z.; Chai, J.; Xu, G.; Wang, Q.; Cui, G., Functional lithium borate salts and their potential application in high performance lithium batteries. Coordination Chemistry Reviews 2015, 292, 56-73.

8. Aravindan, V.; Gnanaraj, J.; Madhavi, S.; Liu, H.-K., Lithium-Ion Conducting Electrolyte Salts for Lithium Batteries. Chemistry - A European Journal 2011, 17 (51), 14326-14346.

9. $\mathrm{Xu}, \mathrm{K}$., Electrolytes and Interphases in Li-Ion Batteries and Beyond. Chemical Reviews 2014, 114 (23), 11503-11618.

10. Zhuang, G.; Xu, K.; Jow, T.; Ross Jr, P., Study of SEI layer formed on graphite anodes in PC/LiBOB electrolyte using IR spectroscopy. Electrochemical and Solid State Letters 2004, 7 (8), A224.

11. $\mathrm{Xu}, \mathrm{M}$;; Tsiouvaras, N.; Garsuch, A.; Gasteiger, H. A.; Lucht, B. L., Generation of Cathode Passivation Films via Oxidation of Lithium Bis(oxalato) Borate on High Voltage Spinel (LiNi0.5Mn1.5O4). The Journal of Physical Chemistry C 2014, 118 (14), 7363-7368.

12. Zhang, Q.; Wang, K.; Wang, X.; Zhong, Y.; Liu, M.; Liu, X.; Xu, K.; Fan, W.; Yu, L.; Li, W., Lithium Bis(oxalate)borate Reinforces the Interphase on Li-Metal Anodes. ACS Applied Materials \& Interfaces 2019, 11 (23), 20854-20863.

13. Dong, Y.; Young, B. T.; Zhang, Y.; Yoon, T.; Heskett, D. R.; Hu, Y.; Lucht, B. L., Effect of Lithium Borate Additives on Cathode Film Formation in LiNi0.5Mn1.5O4/Li Cells. ACS Applied Materials \& Interfaces 2017, 9 (24), 20467-20475.

14. Yang, L.; Wang, P.; Zhao, D.; Wei, Y.; Han, Y.; Zeng, S.; Wang, C.; Li, S., Study on boroncontaining electrolytes at extra-high temperatures for lithium-ion batteries. Sustainable Energy \& Fuels 2020, 4 (8), 4126-4136.

15. Cui, X.; Zhang, H.; Li, S.; Li, X.; Feng, H., Electrochemical performances of a novel lithium bis(oxalate)borate-based electrolyte for lithium-ion batteries with $\mathrm{LiFePO} 4$ cathodes. Ionics 2014, 20 (6), 789-794.

16. Balakrishnan, P.; Ramesh, R.; Kumar, T. P., Safety mechanisms in lithium-ion batteries. Journal of Power Sources 2006, 155 (2), 401-414.

17. Jiang, J.; Dahn, J., Comparison of the thermal stability of lithiated graphite in LiBOB EC/DEC and in LiPF6 EC/DEC. Electrochemical and Solid State Letters 2003, 6 (9), A180.
18. Ha, S.-Y.; Han, J.-G.; Song, Y.-M.; Chun, M.-J.; Han, S.-I.; Shin, W.-C.; Choi, N.-S., Using a lithium bis(oxalato) borate additive to improve electrochemical performance of high-voltage spinel $\mathrm{LiNi} 0.5 \mathrm{Mn} 1.5 \mathrm{O} 4$ cathodes at $60^{\circ} \mathrm{C}$. Electrochimica Acta 2013, 104, 170-177.

19. Pieczonka, N. P. W.; Yang, L.; Balogh, M. P.; Powell, B. R.; Chemelewski, K.; Manthiram, A.; Krachkovskiy, S. A.; Goward, G. R.; Liu, M.; Kim, J.-H. J. J. O. P. C. C., Impact of Lithium Bis(oxalate)borate Electrolyte Additive on the Performance of High-Voltage Spinel/Graphite Li-Ion Batteries. 2013, 117 (44), 22603-22612.

20. Zhu, Y.; Li, Y.; Bettge, M.; Abraham, D. P., Electrolyte additive combinations that enhance performance of high-capacity Li1. 2Ni0. $15 \mathrm{Mn} 0$. 55Co0. 1O2-graphite cells. Electrochimica Acta 2013, 110, 191-199.

21. An, S. J.; Li, J.; Daniel, C.; Mohanty, D.; Nagpure, S.; Wood, D. L., The state of understanding of the lithium-ion-battery graphite solid electrolyte interphase (SEI) and its relationship to formation cycling. Carbon 2016, 105, 52-76.

22. Zhao, H.; Yu, X.; Li, J.; Li, B.; Shao, H.; Li, L.; Deng, Y., Film-forming electrolyte additives for rechargeable lithium-ion batteries: progress and outlook. Journal of Materials Chemistry A 2019, 7 (15), 8700-8722.

23. $\mathrm{Xu}, \mathrm{K}$., Nonaqueous Liquid Electrolytes for Lithium-Based Rechargeable Batteries. Chemical Reviews 2004, 104 (10), 4303-4418.

24. Rauh, R. D.; Brummer, S. B., The effect of additives on lithium cycling in methyl acetate. Electrochimica Acta 1977, 22 (1), 85-91.

25. Abraham, K. M.; Goldman, J. L.; Natwig, D. L., Characterization of Ether Electrolytes for Rechargeable Lithium Cells. Journal of The Electrochemical Society 1982, 129 (11), 2404-2409.

26. Choi, N.-S.; Yew, K. H.; Kim, H.; Kim, S.S.; Choi, W.-U., Surface layer formed on silicon thinfilm electrode in lithium bis(oxalato) borate-based electrolyte. Journal of Power Sources 2007, 172 (1), 404-409.

27. Celik Kucuk, A.; Minato, T.; Yamanaka, T.; Abe, T., Effects of LiBOB on salt solubility and BiF3 electrode electrochemical properties in fluoride shuttle batteries. Journal of Materials Chemistry A 2019, 7 (14), 8559-8567.

28. Fan, L.-Z.; Xing, T.; Awan, R.; Qiu, W., Studies on lithium bis(oxalato)-borate/propylene carbonate-based electrolytes for Li-ion batteries. Ionics 2011, 17 (6), 491-494. 
29. Barth, W. V.; Peña Hueso, A.; Zhou, L.; Lyons, L. J.; West, R., Ionic conductivity studies of LiBOB-doped silyl solvent blend electrolytes for lithium-ion battery applications. Journal of Power Sources 2014, 272, 190-195.

30. Xu, K.; Lee, U.; Zhang, S.; Wood, M.; Jow, T. R., Chemical analysis of graphite/electrolyte interface formed in LiBOB-based electrolytes. Electrochemical and solid-state letters 2003, 6 (7), A144-A148.

31. Lee, S. J.; Han, J.-G.; Park, I.; Song, J.; Cho, J.; Kim, J.-S.; Choi, N.-S., Effect of lithium bis (oxalato) borate additive on electrochemical performance of Li1. 17Ni0. 17Mn0. 5Co0. $17 \mathrm{O} 2$ cathodes for lithium-ion batteries. Journal of The Electrochemical Society 2014, 161 (14), A2012.

32. Yu, B.-T.; Qiu, W.-H.; Li, F.-S.; Xu, G.-X., The electrochemical characterization of lithium bis (oxalato) borate synthesized by a novel method. Electrochemical and Solid State Letters 2005, 9 (1), A1.

33. Lian, F.; Li, Y.; He, Y.; Guan, H.; Yan, K.; Qiu, W.; Chou, K.-C.; Axmann, P.; WohlfahrtMehrens, M., Preparation of LiBOB via rheological phase method and its application to mitigate voltage fade of Li1.16[Mn0.75Ni0.25]0.84O2 cathode. RSC Advances 2015, 5 (105), 86763-86770.

34. Lestariningsih, T.; Wigayati, E.; Ratri, C.; Sabrina, Q., Study of LiBOB compound synthesis by vacuum process as lithium ion battery electrolytes. Journal of Physics: Conference Series 2017, 817, 012030 .

35. Lischka, U.; Wietelmann, U.; Wegner, M., German Pat. DE 19829030 C1 (1999);(b) W. Xu and CA Angell. Electrochem. Solid-State Lett 2001, 4, E1.

36. Zavalij, P. Y.; Yang, S.; Whittingham, M. S., Structures of potassium, sodium and lithium bis (oxalato) borate salts from powder diffraction data. Acta Crystallographica Section B: Structural Science 2003, 59 (6), 753-759.

37. Hubbard, C., EH Evans and DK Smith. J. Appl. Crystallogr 1976, 9, 169.

38. Halwax, E. In The Full-Pattern Reference Intensity Ratio Method in Quantitative Phase Analysis, Materials Science Forum, Trans Tech Publ: 1998; pp 93-99.

39. Hillier, S., Accurate quantitative analysis of clay and other minerals in sandstones by XRD: comparison of a Rietveld and a reference intensity ratio (RIR) method and the importance of sample preparation. Clay minerals 2000, 35 (1), 291-302.
40. Yang, L.; Furczon, M.; Xiao, A.; Lucht, B.; Zhang, Z.; Abraham, D., Effect of impurities and moisture on lithium bisoxalatoborate (LiBOB) electrolyte performance in lithium-ion cells. Journal of Power Sources 2010, 195 (6), 1698-1705.

41. Li, C.; Li, Z.; Wang, P.; Liu, H.; Zhao, D.; Wang, S.; Li, S., Studies of air-exposure effects and remediation measures on lithium bis(oxalato)borate. New Journal of Chemistry 2019, 43 (36), 1423814245.

42. Xu, K.; Deveney, B.; Nechev, K.; Lam, Y.; Jow, T. R., Evaluating LiBOB/lactone electrolytes in large-format lithium-ion cells based on nickelate and iron phosphate. Journal of The Electrochemical Society 2008, 155 (12), A959.

43. Xu, K.; Zhang, S.; Jow, T. R.; Xu, W.; Angell, C. A., LiBOB as salt for lithium-ion batteries: a possible solution for high temperature operation. Electrochemical and Solid State Letters 2001, 5 (1), A26.

44. Wigayati, E. M.; Lestariningsih, T.; Subhan, A.; Ratri, C. R.; Purawiardi, I., Synthesis and characterization of LiBOB as electrolyte for lithiumion battery. Ionics 2016, 22 (1), 43-50.

45. Yu, B.-T.; Qiu, W.-H.; Li, F.-S.; Xu, G.-X., The Electrochemical Characterization of Lithium Bis(oxalato)borate Synthesized by a Novel Method. Electrochemical and Solid-State Letters 2006, 9 (1), A1.

46. Wang, S.; Qiu, W.; Li, T.; Yu, B.; Zhao, H., Properties of Lithium bis (oxatlato) borate (LiBOB) as a Lithium Salt and cycle performance in LiMn2O4 Half Cell. Int. J. Electrochem. Sci 2006, 1, 250-257.

47. Wachtler, M.; Wohlfahrt-Mehrens, M.; Ströbele, S.; Panitz, J.-C.; Wietelmann, U., The behaviour of graphite, carbon black, and Li 4 Ti $5 \mathrm{O}$ 12 in LiBOB-based electrolytes. Journal of applied electrochemistry 2006, 36 (11), 1199-1206. 